\title{
Genes Regulating Maternal Recognition of Pregnancy in Domestic Animals: an Update
}

\author{
Avantika Mor ${ }^{1}$, Sukanta Mondal ${ }^{1 *}$ Ippala Janardana Reddy ${ }^{1}$ and N.P Soumya ${ }^{2}$ \\ ${ }^{I}$ National Institute of Animal Nutrition and Physiology; Adugodi - India. ${ }^{2}$ National Dairy Research Institute; (SRS), \\ Bangalore -India
}

\begin{abstract}
Early embryonic mortality is one of the main sources of reproductive wastages and major constraints for full exploitation of the production potential of livestock. The survivality of embryo during early embryonic life is mostly dependent on the efficiency with which the maternal recognition of pregnancy (MRP) is established. Maternal recognition of pregnancy involves molecular dialogue between the trophoblast of conceptus and uterine endometrium. Embryonic development to the blastocyst stage and uterine differentiation to the receptive environment are crucial for successful establishment of the embryo-uterine cross-talk that leads to the initiation and progression of successful implantation. Unravelling the complex intricate molecular and cellular dialogues between the conceptus and uterine environment will facilitate development of strategies to augment early embryo survivality.
\end{abstract}

Key words: embryonic mortality, maternal recognition of pregnancy, embryo-uterine cross-talk

\section{INTRODUCTION}

Successful establishment of pregnancy in the mammals involves concerted events where the uterus and terminally differentiated embryos exchange signals culminating in maternal recognition of pregnancy (MRP). Recent advances in molecular and genetic approaches have led to the discovery of few molecules involved in embryo-uterine dialogue; however, a comprehensive understanding of the MRP and implantation process is still not deciphered. Among various developmental events during early pregnancy, implantation of embryo is a critical step and its success mostly depends on the efficiency with which the MRP is established. The MRP involves the complex cellular and molecular cross-talking between the trophoblast of conceptus and uterine endometrium at embryo-uterine interface. In ruminant, the principal signal for
MRP is identified to be interferon- 1 secreted by trophoectoderm of blastocyst for a limited period during early pregnancy. Interferon- $\iota$ exerts its antiluteolytic action by suppressing the normal pattern of pulsatile release of PGF $2 \alpha$ in late estrous cycle, possibly by a mechanism that involves down regulation of estrogen receptor in uterine epithelium, which in turn prevents a rise in oxytocin receptor. The survivability and opportunity of successful development of an embryo are generally influenced directly and indirectly by various paracrine and autocrine factors (steroid hormones, growth factors, and cytokines), controlling uterine microenvironment. Out of these factors, hormones such as $\mathrm{PGF}_{2 \alpha}$, $\mathrm{PGE}_{2}$, integrin, COX-II, osteopontin and galectin released during the pre-implantation period influence molecular interactions involved in MRP and maintenance of pregnancy through reciprocal

\footnotetext{
*Author for correspondence: sukanta781@gmail.com
} 
interactions between the conceptus and endometrium (Spencer et al. 1996).

The recent advent of state-of-the-art transcriptomic and proteomic technologies allows, for the first time, a holistic analysis of mechanisms involved in signaling between an embryo and its maternal environment before implantation. Proteome and transcriptome studies have revealed quantitative and qualitative changes in the genes at different stages of the estrous cycle and pregnancy (Bauersachs et al. 2005). These spatial and temporal changes were mainly due to the expression pattern of sets of genes in the uterine environment, where the endometrium is especially important for the embryo-maternal interaction and successful establishment of pregnancy. This review focuses primarily on the MRP and genes controlling its events that facilitate the development of optimal reproductive management strategies and paradigm to reduce early embryonic wastage in livestock.

\section{MATERNAL RECOGNITION OF PREGNANCY (MRP)}

Higher rates of early embryonic mortality is a major cause of reproductive failure during preimplantation period in livestock. These preimplantation losses are associated with inadequate luteal function during early pregnancy in ruminants (Mondal and Prakash 2002). The survivality of embryo during early embryonic life is mostly dependent on the efficiency with which the MRP is established. MRP was coined by Roger Short and defined as the physiological process whereby the conceptus signaled its presence to the maternal system and prolonged the lifespan of the corpus luteum (CL). Progesterone produced by the CL acts on the uterus to stimulate and maintain uterine functions that are conducive for early embryonic development, implantation, placentation and successful fetal and placental development to term (Mondal et al. 2007; 2010). The MRP occurs between days 16-19, 12-13 and around day 17 of pregnancy in cow, sheep and goat, respectively. During the MRP, the mononuclear cells of the conceptus trophectoderm synthesize and secrete IFN $\tau$ between Days 10 and 21 to 25 with maximal production on Days 14 to 16 (Roberts et al. 1999). IFN $\tau$ appears to be the sole factor produced by the conceptus that prevents the development of the endometrial luteolytic mechanism. IFN-1 does not act to stabalize the PR expression in the endometrial epithelium during the pregnancy; however, IFN-1 acts in a paracrine fashion on endometrial LE and GE to suppress the transcription of ER $\alpha$ and OTR genes (Spencer and Bazer 1996; Fig. 1). In vitro culture of sheep conceptus homogenates and analysis for radiolabelled proteins released into the culture medium indicates that oTP-1 is secreted by the mononuclear cells of ovine trophoectoectoderm. oTP-1 is secreted in two phases: one between days 10 and 21 of pregnancy, and second by the chorion between days 25 and 45 of pregnancy. oTP-1 is thought to exert a paracrine antiluteolytic effect on the endometrium as there is no evidence that it is transported from the uterus to directly affect CL. Secretion of oTP-1 (ng/uterine flushing) begins on about 10 and increases with the morphological changes: from spherical (312 $\mathrm{ng})$ to tubular (1380 $\mathrm{ng}$ ) to filamentous (4455 $\mathrm{ng}$ ) forms on days 12-13 (Spencer et al. 1996). Goat conceptus secretes caprine IFN-tau between days 16-21 that is assumed to be antiluteolytic signal. Intra-uterine injections of recombinant o IFN-tau in cyclic goats extend CL lifespan in the goats. The endocrine-exocrine theory of maternal recognition of pregnancy in the pigs has been studied. It is assumed that uterine endometrium secrets luteolysin $\mathrm{PGF}_{2 \propto}$ and that the conceptus secretes estrogen that are antiluteolytic. The present theory is that $\mathrm{PGF}_{2 \propto}$ is secreted in an endocrine direction towards uterine vasculature in cyclic gilts and transported to CL to exert its luteolytic effect. However, in pregnant pigs, the direction of secretetion of PGF is exocrine into uterine lumen where it is sequestered to exert its biological effects in utero and / or to be metabolized to prevent luteolysis.

\section{GENES REGULATING MATERNAL RECOGNITION OF PREGNANCY INTERFERRON-TAU (IFN--é)}

IFN-1 is a member of the Type I IFN family that acts differentially on the endometrial luminal epithelium (LE), glandular epithelium (GE) and stroma to regulate expression of a number of IFNstimulated genes (ISGs) that are hypothesized to play roles in the endometrial differentiation and conceptus implantation (Hansen et al. 1999). It is a subclass of the 172 amino acids type I omega (w) IFNs, which competes with IFN $\alpha$ and $\beta$ for binding of a common cell surface receptor. IFN-is of cattle and sheep arise from multiple mRNAs, 
approximately $1 \mathrm{~kb}$ in length, which arise from multiple genes. Like other type I interferon genes, IFN-1 genes are intronless and consist of $585 \mathrm{bp}$ ORF coding for a 195 amino acids preprotein containing a 23 signal sequence, which after cleavage yield a mature protein of 172 amino acids. Bovine IFN-1 transcripts contain potential $\mathrm{N}$-glycosylation site at Asn78 and multiple glycosylation variants are present in the secreted proteins. Bovine, ovine and caprine IFN- 1 are more similar in sequence to each other than bIFNw. In the coding region, the nucleotide sequences exhibit approximately $90 \%$ identity and their inferred amino acid sequence about $80 \%$ identity (Roberts et al. 1999). The predicted amino acid identity between bIFN-1 and IFN $\alpha 1$ and IFNw is $50 \%$ and $72 \%$, respectively.

Recently, Saugandhika et al. (2013) reported 13 distinct IFN- $\tau$ cDNA variants that encoded for eight distinct buffalo IFN- $\tau$ isoforms. These buffalo IFN- $\tau$ isoforms had a greater nucleotide and amino acid homology with caprine IFN- $\tau$ (98$100 \%$ and $96-100 \%)$ than ovine $(94-97 \%$ and $90-$ $95 \%)$ and bovine (89.6-90.6\% and $82-86 \%$ ), respectively. The novel buffalo IFN- $\tau$ isoforms showed pronounced nucleotide and amino acid sequence identity with one another (99.1-99.8\% and $98-99 \%$ ) but only moderate identity with previously identified buffalo IFN- $\tau$ (90-92\% and $82-86 \%)$. IFN-1 acts differently on the endometrial LE, GE and stroma to regulate expression of various IFN stimulated genes (ISGs) that play crucial roles in endometrial differentiation and implantation of conceptus. The actions of IFN- 1 to signal pregnancy recognition and induce or increase expression of ISGs including ISG15 are dependent on the effects of progesterone. Type 1 IFN receptor subunits - IFNAR1 and IFNAR2 are expressed in all endometrial cell types with highest expression in endometrial LE. The majority of ISGs are induced or increased in response to the conceptus or IFN $\gamma$ only in endometrial stroma and middle to deep GE of the ovine uterus. In sheep, IFN-1 does not induce ISG in endometrial LE and sGE due to expression of potent repressor of gene transcription of IFN regulatory factor 2 (IRF 2). Bazer et al. (1997) proposed the mechanism of action of IFN-1 on endometrial cells. oIFN- 1 binds to a dimeric IFN-R whose intracellular domain binds tyrosine kinases (Janus kinases, JAKs). After binding of IFN-1, JAKs viz., JAK1 and Tyk2 are activated and subsequently phosphorylate tyrosine residues of signal transducers and activators of transcription (STATs: STAT1, STAT1A, STAT2). The STATs dimerize and bind DNA binding protein to form trimeric interferon simulated gene factor (ISGF) complex which then translocates to the nucleus where it binds an interferon stimulated regulatory element (ISRE) resulting in expression of the IRF-1 gene. The product of this gene in turn activates the expression of negative acting transcription factor IRF2, which interact with other regulatory elements to control the expression of IFNresponsive genes including the OTR and ERs.

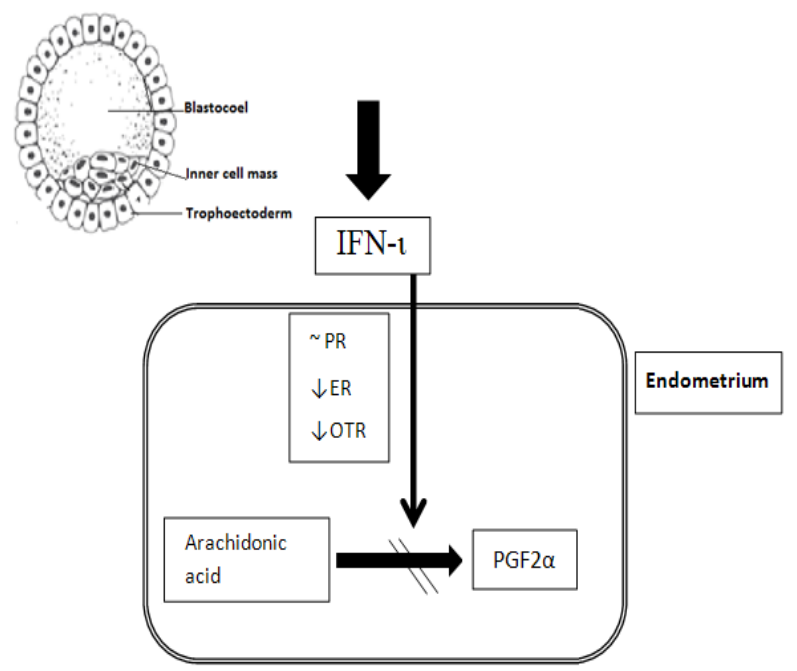

Figure 1 - Interferron tau (IFN-1) production resulting from embryo-uterine crosstalking during early pregnancy in mammals. During maternal recognition of pregnancy, trophoectoderm of embryo produces IFN-1 which stabilizes progesterone receptor $(\mathrm{PR})$ and reduces the number of estrogen receptor (ER) and oxytocin receptor (OTR) resulting in attenuation of uterine luteolysin, $\mathrm{PGF}_{2 \alpha}$. This pathway results in maintenance of corpus luteum function.

\section{CYCLOOXYGENASE 2 (COX 2)}

Prostaglandins (PGs) are the major contributors to the regulation of reproductive processes and successful establishment of pregnancy (Mondal 2009). The production of endometrial PGs is mainly governed by the rate-limiting enzymes, cyclooxygenase (COX)-1 and COX-2, also known as prostaglandin endoperoxidase $\mathrm{H}$ synthetases 1 and 2 (PGHS-1 and PGHS-2). These enzymes are responsible for the conversion of arachidonic acid into $\mathrm{PGH}_{2}$, the common precursor of the various forms of PGs including $\mathrm{PGE}_{2}$ and $\mathrm{PGF}_{2 \alpha}$. The down stream enzymes, PGE synthase and PGF synthase (PGFS) catalyze the conversion of $\mathrm{PGH}_{2}$ 
to $\mathrm{PGE}_{2}$ and $\mathrm{PGF}_{2 \alpha}$, respectively. $\mathrm{PGE}_{2}$ and $\mathrm{PGF}_{2 \alpha}$ are the major secretory products of uterine endometrium in ruminant. $\mathrm{PGE}_{2}$ is considered important for blastocyst spacing, implantation and decidualization, maternal recognition of pregnancy, regulation of placental blood flow and function and corpus luteum life span and function whereas $\mathrm{PGF}_{2 \alpha}$ acts as the luteolytic agent to control the estrous cycle (Arosh et al. 2004). Tilldate, three isoforms of COXs have been identified. Cyclooxygenase-1 (COX-1) is a glycoprotein of $71 \mathrm{kDa}$, which is constitutively expressed in different tissues. COX-1 is encoded by a gene on chromosome 9 and plays a role in tissue homeostasis by modulating several cellular processes ranging from cell proliferation to angiogenesis or platelet aggregation due to thromboxane production. Cyclooxygenase-2 (COX-2) is the inducible isoform, which is regulated by the growth factors and different cytokines such as IL1â, IL6, or TNFá and overexpressed during inflammation. The COX-2 gene is located on chromosome 1 and its promoter displays an NFêB response element as well as other cytokine-dependent (i.e., IL6) response elements. COX-3 has been identified as a splice variant of COX-1, and it is present mainly in brain and spinal cord. Currently, the role of COX-3 is not known. However, reports suggest a possible role in pain sensitivity, based on the studies focused on the mechanism of action of acetaminophen (paracetamol), evoked as a selective inhibitor of COX-3 (Blitek et al. 2006). Although COX-1 deficient female mice are fertile, they have specific defects in parturition, whereas COX-2 deficient female mice are infertile with abnormalities in ovulation, fertilization, implantation, and decidualization.

\section{PROSTAGLANDIN E SYNTHASE (PGES)}

PGES is a member of the membrane associated protein in eicosanoid and glutathione metabolism (MAPEG) superfamily, which consists of six human proteins with divergent functions. Basically, PGES is a terminal prostanoid synthase that can enzymatically convert cyclooxygenase product $\mathrm{PGH}_{2}$ to $\mathrm{PGE}_{2}$. The activity of PGES has been detected both in cytosolic and microsomal fractions of various cells. Cytosolic PGES (cPGES) is constitutively expressed in a wide variety of cells and tissues and predominantly linked with COX-1 to promote immediate response whereas microsomal PGES (mPGES) is a membrane associated, inducible perinuclear enzyme with glutathione dependent activity and is expressed in variety of tissues, including prostate, testis and small intestine. mPGES is preferentially coupled with inducible COX-2 to promote delayed $\mathrm{PGE}_{2}$ generation. The PGES gene size is $14.8 \mathrm{~kb}$ and has been mapped to chromosome 9. The genomic sequences of human PGES (Acc. No. AC 007936) indicates three exons $(136,83$ and 1526 nt) separated by two introns ( 4.2 and $8.8 \mathrm{~kb}$ ). The complete cDNA sequences of PGES has been characterized in the rat (Acc. No. NM 0211583), cattle (Acc. No. AY 032727), horse (Acc. No. AY 057096) and pig (Acc. No. AY 857634). Filion et al. (2001) reported the complete cDNA sequences of 462 base pairs of bovine PGES (Acc. No. AY 032727). The nucleotide sequence of buffalo PGES cDNA encoding the entire mature peptide, except the first three amino acids are also available (Acc. No. DQ167808). The nucleotide sequence of bubaline mPGES-1 cDNA exhibited 98, 90.5, $89.2,87.2,86.5,80.4,80.4 \%$ identity with that of cattle, pig, dog, human, horse, rat and mouse, respectively (Mondal et al. 2006). Expression of the PGES mRNA has been evaluated in a variety of tissues such as uterus, placenta, corpus luteum and ovary (Arosh et al. 2004; Parent and Fortier 2005; Waclawik et al. 2006; Mondal et al. 2007; 2008).

The expression of PGES mRNA and protein increased with gestation in ovine placenta but no further change with onset or progression of labour or during cortisol infusion (Martin et al. 2002). The expression level of PGES was higher than that of PGFS in growing CL, lower in regressing CL and equal in mature bovine corpus luteum (Arosh et al. 2004). Parent and Fortier (2005) demonstrated that mPGES expression decreased from the beginning of the cycle until days 13-15 and then increased rapidly to reach higher expression at the time of luteolysis (Days 16-18). Waclawik et al. (2006) reported that mPGES-1 expression increased on days 13-15 compared to day 18-21 but no significant variation was observed throughout the cycle in pig. Mondal (2009) reported that expression of mPGES-1 mRNA could not be detected in the cyclic endometrium of buffalo during the first (days 3-5) and second (days 6-15) stages but was observed in the endometrium during the third stage (days 1621) of estrous cycle. Tanioka et al. (2000) 
observed 3-fold increased GSH- dependent PGES activity in vivo after lipopolysaccharide (LPS) challenge in cytosol of rat brain but not of other tissues. Studies have reported that estradiol, oxytocin, LPS and TNF- $\alpha$ increased the production of $\mathrm{PGE}_{2}$ in buffalo endometrial epithelial and stromal cells in vitro (Mondal et al. 2009a, 2009b; 2010). PGES mRNA expression is also increased in the presence of LPS, TNF- $\alpha$ and IFN- 1 in bovine epithelial cells (Parent et al. 2002). They also reported that phorbol -12 myristate 13 acetate increases PGES mRNA, COX-2 mRNA and $\mathrm{PGE}_{2}$ production, suggesting that the expression of PGES was correlated with that of COX-2 for the production of $\mathrm{PGE}_{2}$. Increasing the production would modulate $\mathrm{PGE}_{2} / \mathrm{PGF}_{2 \alpha}$ ratio and contribute to the establishment of pregnancy.

\section{PROSTAGLANDIN F SYNTHASE (PGFS)}

PGFS is a member of aldo-keto reductase (AKR) superfamily based on the substrate specificity, molecular weight and amino acid sequence. AKR superfamily consists of monomeric $\mathrm{NAD}(\mathrm{P}) \mathrm{H}$ dependent oxido-reductase with broad specifity of substrates: endogenous substrates such as steroid hormones, prostaglandins and xenobiotics such as drugs and carcinogens. PGFS gene consists of nine exons and eight introns. The initiation codon is located at exon 1 and stop codon at exon 9 and encode a protein of 323 amino acid residues. Human PGFS gene is spanned around $11.597 \mathrm{~kb}$ and located at chromosome 10. The complete cDNA sequences of PGFS has been characterized in the cattle (Acc. No. J03570), buffalo (Acc. No. DQ884879), sheep (Acc. No. AY135401), horse (Acc. No. AY304536) and pig (Acc. No. AY863054). PGFS is known to exist in six isoforms viz., lung type PGFS (PGFS1), lung type PGFS found in liver (PGFS2), liver type PGFS (DDBX) and three other PGFS isolated from human, sheep and Trypanosoma brucei. All these isoforms belong to the AKR1C subfamily, except from Trypanosoma, which belongs to the AKR5A subfamily. In bovine, six isoforms of PGFS, viz., PGFS1, PGFS2, DDBX, PGFS like 1 (PGFSL1), PGFSL2 and 20 $\alpha$-HSD have been identified (Madore et al. 2003). A new isoform, AKR1B5 possessing aldoreductase activity has been implicated as the most probable enzyme responsible for the production of $\mathrm{PGF}_{2 \alpha}$ in bovines (Madore et al. 2003). Kuchinke et al. (1992) reported the complete cDNA sequence (CDS) of 972 base pairs of bovine lung PGFS (Acc. No. M86544). The cDNA sequences of bovine PGFS like 1 protein (Acc. No AY135400) and PGFS like 2 protein (Acc. No. AY135401) are of 972 base pairs. The nucleotide sequence of buffalo PGFSL2 cDNA exhibited 98, 87.6, 87.3, 77.2, 68.9, 68.7, $65,77.7 \%$ identity with bovine PGFSL2, bovine lung PGFS, bovine liver PGFS, horse, pig, monkey, dog and human, respectively (Mondal et al. 2007). The expression of PGFS mRNA has been studied in the domestic ruminants, including cattle, buffalo, sheep, horse, pig and monkey and rat. Immuno-histochemical studies showed that PGFS proteins were localized in the luminal epithelium and stroma of endometrium and smooth muscle cells of bovine myometrium (Arosh et al. 2004). In corpus luteum, PGFS were localized in the large luteal cells and IFN-1 increased PGES expression ( 2-fold) but not PGFS. Palliser et al. (2004) demonstrated that the expression of PGFS increased in the placentome following dexamethasone induced and spontaneous labour onset in the sheep. Mondal (2009) reported that the expression of PGFSL-2 mRNA could not be detected in buffalo uterine endometrium at any stage of estrous cycle. Xiao et al. (1999) reported that steroid hormones had no significant effect on PGFS expression in bovine endometrial cells. Oxytocin was reported to upregulate PGFS mRNA but rbIFN-1 significantly inhibited this induction at 3, 6, 12 and $24 \mathrm{~h}$, respectively (Xiao et al. 1998). Similarly, Arosh et al. (2004) reported that IFN-1 decreased PGFS expression in endometrium by 1.5 fold and myometrium by 3.5 fold but not in corpus luteum. It has been found that the production of $\mathrm{PGF}_{2 \alpha}$ increased in the presence of estradiol, LPS and TNF- $\alpha$ in epithelial and stromal cells of buffalo (Mondal et al. 2009a; 2009b; 2010). The growth of buffalo uterine epithelial cells were significantly $(\mathrm{P}<0.05)$ higher in the presence of LPS, TNF- $\alpha$, linoleic acid and linolenic acid (Nandi et al. 2012) as compared to the control and lower doses. Progesterone, estradiol and oxytocin did not significantly increase the growth of buffalo uterine epithelial cells.

\section{GALECTIN}

Galectins belongs to a family of calciumindependent â-galactoside-binding proteins, lectin superfamily and involved in immunomodulation, 
cell adhesion and defence against invading microorganisms. Galectins do not possess a signal peptide or transmembrane spanning domain, and are secreted from the cells by a nonclassical pathway. Several forms of galectins: galectin-1 (LGALS1), galectin-3 (LGALS3), Galectin-5 (LGALS5), Galectin-9 (LGALS9) and Galectin-15 (LGALS15) have been discovered. Galectin-1 possess adhesive and anti-adhesive roles, immunomodulator in maternofetal tolerance as well as embryo implantation. However, galectin-1null mouse embryos develop normally and do not produce any overt phenotypic abnormalities (Poirier and Robertson ${ }^{32}$ ). Galectin-3 (LGALS3) is a galactose-specific lectin, expression of which increases significantly during the secretory phase of the menstrual cycle (von Wolff et al. 2005). Mice lack both galectins-1 and -3 implant normally but a further family member, galectin-5, is present and may compensate. Galectin- 9 has been identified in mid- and late-secretory and decidual phases in human endometrium, with the expression in glandular and luminal epithelial but not stromal or immune cells (Smalley and Ley 2005). Recently, a new galectin family member, galectin-15, has been discovered in the endometrium of sheep, which has a prospective role in trophectoderm attachment (Farmer et al. 2008). Ovine endometrial Galectin-15 contains a conserved carbohydrate recognition domain (CRD) that binds $\beta$-galactosides, but the carbohydrate-binding specificity for each galectin appears to be different. In addition to a conserved CRD, it also contains predicted cell attachment sequences (LDV and RGD) that could mediate binding to integrins in the ECM proteins (Kimber and Spanswick 2000). Galectin-15 mRNA was detected only in the endometrial LE and superficial ductal GE (Gray et al. 2004) of ovine uterus and was not detected before day 10 , appeared and then increased 13 -fold between days 10 and 14, and then noticeably decreased between days 14 and 16 in cyclic, but not pregnant ewes. It was present at low levels on days 10 and 12 , but was abundant on days 14 and 16 of pregnancy in uterine flushing. The proposed extracellular role of galectin- 15 in the uterine lumen is functionally to bind and cross-link $\beta$-galactosides on glycoproteins, such as mucins, integrins, fibronectin, laminin and other glycoproteins and glycolipids, thereby allowing it to function as a heterophilic cell adhesion molecule bridging the blastocyst and the endometrial LE.

\section{OSTEOPONTIN (OPN)}

OPN belongs to the member of the small integrinbinding ligand, N-linked glycoprotein (SIBLING) family of genetically related ECM proteins recognized as key players in a number of diverse processes such as bone mineralization, cellmediated immune responses, inflammation, angiogenesis, cell survival and implantation (Butler et al. 1996). It is a negatively-charged acidic hydrophilic protein of approximately 300 amino acid residues, and is secreted into all body fluids. The OPN cDNA from various mammalian species exhibits a high degree of sequence homology. There is evidence of alternative splicing, although its functional significance is unclear. The molecule undergoes considerable post-translational modification, and is phosphorylated and glycosylated. OPN has an arginine-glycine-aspartic acid (RGD) cell binding sequence, a calcium binding site and two heparin binding domains. In general, OPN is a monomer ranging in length from 264 to 301 amino acids that undergoes extensive posttranslational modification, including phosphorylation, glycosylation, and cleavage, resulting in molecular mass variants ranging from 25 to $75 \mathrm{kDa}$. OPN contains a hydrophobic leader sequence characteristic of a secreted protein, a potential calcium phosphate aspatite binding region of consecutive asparagine residues, a cell attachment GRGDS sequence, a thrombin cleavage site, and two glutamines that are recognized substrates for transglutaminase-supported multimer formation. Genes encoding OPN have been cloned from eight species, including rat, mouse, human, cow, chicken, rabbit and sheep. The cDNA sequences from these species reveal only moderate conservation except in the $\mathrm{NH}_{2}$-terminal region, around the Arg-Gly-Asp (RGD) integrin-binding sequence, and the COOH-terminus.

Multiple forms of OPN have been identified as products of normal and transformed cells derived from rodent tissues. Osteopontin gene in buffalo encodes a protein of 280 amino acids and has insertion of two amino acids at positions 94 (Aspartic acid) and 227 (Asparagine), thus making a total of 280 amino acids as compared to 278 amino acids in bovines and ovines (Tantia et al. 2008). Multiple integrin receptors for OPN are present on trophoblasts and LE of humans and domestic animals, some of which increase during the peri-implantation period (Johnson et al. 2001). 
Evidence suggests that secreted OPN binds integrin receptors expressed on conceptus trophoblast and endometrial LE, where it can stimulate changes in proliferation, migration, survival, adhesion and remodeling of the conceptus as it elongates, apposes and adheres to the LE. OPN is hypothesized to serve as a bifunctional bridging ligand that mediates the adhesion between LE and trophoblast essential for implantation and placentation (Johnson et al. $2003)$. OPN binds to integrin heterodimers ( $\alpha v \beta 1$, $\alpha v \beta 3, \alpha v \beta 5, \alpha v \beta 6, \alpha v \beta 8, \alpha 4 \beta 1, \alpha 5 \beta 1$ and $\alpha 8 \beta 1)$ via its Arg-Gly-Asp (RGD) sequence, and to $\alpha 4 \beta 1$ and $\alpha 9 \beta 1$ by other sequences to promote cell adhesion, spreading and migration. In sheep, OPN is also a component of histotroph secreted from endometrial GE into the uterine lumen during pregnancy. During the peri-implantation period of pregnancy in sheep, OPN mRNA is expressed only by the endometrial glands, is first detected in some glands of some ewes by day 13, and is present in all glands by day 19 (Johnson et al. 2003).

\section{INTEGRINS}

Integrins belong to a family of heterodimeric intrinsic transmembrane glycoprotein receptors that play a major role in cellular differentiation, motility and adhesion. They mediate the interactions with ECM to transduce cellular signals in uterine epithelial cells and conceptus trophoblast (Johnson et al. 2003). The central role of integrins in the implantation adhesion cascade is to bind ECM ligand(s) to cause cytoskeletal reorganization, stabilize adhesion, and mediate cell migration, proliferation and differentiation through numerous signaling intermediates. Altered expression of integrins is correlated with several causes of infertility, null mutations of several integrins leads to peri-implantation lethality and functional blockade of selected integrins reduces the number of implantation sites (Illera et al. 2000). Integrin subunits $\alpha(v, 4,5)$ and $\beta(1,3$ and 5) are constitutively expressed on the apical surfaces of both conceptus trophoblast and endometrial LE during the peri-implantation period of pregnancy in ewes (Johnson et al. 2003). These integrin subunits are detected at the apical surfaces of the LE and GE and on conceptus trophoblast; expression of these integrins is constitutive and not influenced by pregnancy or presence of the conceptus. In the sheep, receptivity to implantation does not appear to involve changes in either temporal or spatial patterns of integrin expression, but may depend on expression of other glycoproteins and ECM proteins, such as galectin15 , OPN and fibronectin, which are ligands for heterodimers of these integrins (Johnson et al. 2003). In species such as pig, mouse and humans, interactions between specific integrins and ECM proteins frame the putative window of implantation (Carson et al. 2000). A 2310 bp long buffalo (Bubalus bubalis) cDNA sequence of Integrin b2 (ITGB2) gene was characterized (Sharma et al. 2010). At nucleotide level, buffalo ITGB2 exhibited 96-98\% homologies with other ruminants such as cattle, bison, sheep, goat and deer. The transmembrane and cytoplasmic regions are highly conserved among buffalo and other ruminants.

\section{CONCLUSION}

This review has highlighted maternal recognition of the pregnancy (MRP) and factors/genes controlling the pregnancy recognition signalling at embryo-uterine interface. Understanding of the factors/genes regulating the conceptus development and exploration of the signal transduction systems that permit the reciprocal regulation of trophoectoderm and adjacent endometrial cells could facilitate the development of future strategies to ameliorate the early embryonic losses. Perturbations of the MRP by environmental factors such as heat stress, nutritional stress, etc. can cause altered cellular function, leading to early embryonic mortality. Unravelling the complex molecular dialogue between the conceptus and uterine environment under heat and nutritional stress might facilitate the development of management strategies to improve fertility under climate change scenario. With increasing concern worldwide focused on climate change and food security, it is crucial that nutritional strategies to improve the reproductive outcome and environmental footprint of such developments are considered, including the predicted changes in feedstuff availability. Identification of novel genes at this transition event and defining their functional significance could provide vital information to identify reasons of aberrant MRP. Uterine- or embryo-specific conditional knockout of genes of interest is urgently needed to better understand the definitive 
roles played by these genes in the MRP and implantation. A genome-wide screening approach coupled with functional assays might help elucidate these complex signaling pathways.

\section{AUTHOR CONTRIBUTIONS}

The authors Avantika Mor and Sukanta Mondal contributed equally to this work.

\section{ACKNOWLEDGEMENTS}

We are thankful to National Agricultural Science Fund (formerly National Fund for Basic, Strategic and Frontier Application Research in Agriculture), Ministry of Agriculture, ICAR, New Delhi for providing financial support to carry out the work. The authors express their gratitude to Dr. A. Bandyopadhyay, Ex. National Coordinator and Dr. P. K. Agarwal, ADG (NASF) for their help and suggestions. We thank the Director, NIANP, for providing the necessary facilities for conducting the research work. The help rendered by A. Jagannath is duly acknowledged.

\section{REFERENCES}

Arosh JA, Banu SK, Kimmins S, Chapdelaine P, Mac Laren LA, Fortier MA. Effect of interferon-tau on prostaglandin biosynthesis, transport and signaling at the time of maternal recognition of pregnancy in cattle: evidence of polycrine action of prostaglandin $\mathrm{E}_{2 .}$ Endocrinol. 2004; 145: 5280-5293.

Bauersachs S, Ulbrich SE, Gross K. Gene expression profiling of bovine endometrium during the oestrous cycle: detection of molecular pathways involved in functional changes. J Mol Endocrinol. 2005; 34: 889908.

Bazer FW, Spencer TE, Ott TL. Interferon tau: a novel pregnancy recognition signal. American J Reprod Immunol. 1997; 37: 412-420.

Blitek A, Waclawik A, Kaczmarek MM, Stadejek T, Pejsak Z, Ziecik AJ. Expression of cyclooxygenase-1 and -2 in the porcine endometrium during the oestrous cycle and early pregnancy. Reprod Domestic Anim. 2006; 41: 251-257.

Butler WT, Ridall AL, McKee MD. Osteopontin. In: Principals of Bone Biology, New York: Academic Press. pp.167-181 1996.
Carson DD, Bagchi I, Dey SK, Enders AC, Fazleabas AT, Lessey BA, et al. Embryo implantation. Dev Biol. 2000; 223: 217-237.

Farmer JL, Burghardt RC, Jousan FD, Hansen PJ, Bazer FW, Spencer TE. Galectin 15 (LGALS15) functions in trophectoderm migration and attachment. FASEB J. 2008; 22: 548-560.

Gray CA, Adelson DL, Bazer FW, Burghardt RC, Meeusen EN, Spencer TE. Discovery and characterization of an epithelial-specific galectin in the endometrium that forms crystals in the trophectoderm. Proc Natl Acad Sci USA. 2004; 101: 7982.

Hansen TR, Austin KJ, Perry DJ, Pru JK, Teixeira MG, Johnson GA. Mechanism of action of interferontau in the uterus during early pregnancy. J Reprod Fertil. 1999; 54: 329-339.

Illera MJ, Cullinan E, Gui Y, Yuan L, Beyler SA, Lessey BA. Blockade of the alpha (v) beta (3) integrin adversely affects implantation in the mouse. Biol Reprod. 2000; 62: 1285-1290.

Johnson GA, Bazer FW, Jaeger LA, Ka H, Garlow JE, Pfarrer C, et al. Muc-1, integrin, and osteopontin expression during the implantation cascade in sheep. Biol Reprod. 2001; 65: 820-828.

Johnson GA, Burghardt RC, Joyce MM, Spencer TE, Bazer FW, Gray CA, et al. Osteopontin is synthesized by uterine glands and a $45-\mathrm{kDa}$ cleavage fragment is localized at the uterine-placental interface throughout ovine pregnancy. Biol Reprod. 2003; 69: 92-98.

Kimber SJ, Spanswick C. Blastocyst implantation: the adhesion cascade, Seminars Cell Dev Biol. 2000; 11: 77-92.

Kuchinke W, Barski O, Watanabe K, Hayaishi O. A lung type prostaglandin $\mathrm{F}$ synthase is expressed in bovine liver: cDNA sequence and expression in E.coli, Biochem Biophy Res Comm. 1992; 183: 12381244.

Martin RL, Whittle WL, Gyomarey S, Gribb W, Challis JRG. Ontogeny and regulation of ovine placental prostaglandin E synthase. Biol Reprod. 2002; 67: 868-873.

Madore E, Harvey N, Parent J, Chapdelaine P, Arosh JA, Fortier MA. An aldose reductase with $20 \propto$ hydroxysteroid dehydrogenase activity is most likely the enzyme responsible for the production of prostaglandin $\mathrm{F}_{2 \propto}$ in the bovine endometrium. $\mathrm{J}$ Biol Chem. 2003; 278: 11205-11212.

Mondal S, Prakash BS. Comparison of luteal function between cows and buffaloes during estrous cycle. Ind J Dairy Sci. 2002; 55: 142-144. 
Mondal S, Varshney VP, Kumar N, Shukla SN, Sukumar K, Agarwal SK, Joshi P, Sharma AK, Mitra A. Cloning and molecular characterization of prostaglandin E synthase gene in buffalo (Bubalus bubalis), In : Proc. of Symposium in Frontier in Reproduction : Concepts and Applications in Genomic Era in India, 2006, Karnal; p. 73.

Mondal S, Varshney VP, Sukumar K, Kumar N, Shukla SN, Agarwal SK, Joshi P, Mitra A. Molecular characterization of prostaglandin $\mathrm{F}$ synthase gene in buffalo (Bubalus bubalis), In : Proc. of Section of Medical Sciences (including Physiology), $94^{\text {th }}$ Indian Science Congress Association in India, 2007, Chidambaram; p. 17-18.

Mondal S, Prakash BS, Palta P. Endocrine aspects of estrous cycle in buffalo: an overview. Asian Australasian J Anim Sci. 2007; 20: 124-131.

Mondal S, Varshney VP, Mitra A. Prostaglandin E and F synthases: genomic insight, In: Proceedings of National Symposium on Animal Biotechnology in India, 2007, Bangalore, p. 34-40.

Mondal S, Varshney VP, Mitra A. Early Embryonic Mortality : Physiogenomic approaches, Lead Paper presented at National symposium on Current Concepts in Productivity Management in Livestock and Poultry-Environment, Nutrition and Stress in India, 2008; p. 47-57.

Mondal S. Early embryonic loss: Genomic insight. Ind. J Physiol Allied Sci. 2009; 63: 44-51.

Mondal S, Nandi S, Reddy IJ, Suresh KP. Effect of steroids on in vitro prostaglandin production in buffalo endometrial epithelial cells, In: Proceedings of XVIII Annual SAPI conference and National Symposium on Physiogenomic prospects in augmenting Livestock Production in India 2009a, Bangalore, p. 170.

Mondal S, Nandi S, Reddy IJ, Suresh KP. Regulation of prostaglandin production by steroid hormones in buffalo endometrial stromal cells, In: Proceedings of XVIII Annual SAPI conference and National Symposium on Physiogenomic prospects in augmenting Livestock Production in India 2009b, Bangalore, p. 170.

Mondal S, Reddy IJ, Nandi S. Modulation of prostaglandin production by LPS and TNF in endometrial epithelial and stromal cells of buffalo, In: Proceedings of XXXVIII Dairy Industry Conference in India, 2010, NIMHANS, Bangalore; 2010. P. 7.

Mondal S, Suresh KP, Nandi S. Endocrine profiles of estrous cycle in buffalo - A meta-analysis. Asian Australasian J Anim Sci. 2010; 23: 169-172.

Nandi S, Mondal S, Reddy IJ. Effect of prostaglandin producing modulators on in vitro growth characteristics in buffalo endometrial epithelial cells. Theriogenol. 2012; 77: 1014-1020.
Palliser HK, Ooi GT, Hirst JJ, Rice G, Dellions NL, Escalon RM, et al. Changes in the expression of prostaglandin $\mathrm{E}$ and $\mathrm{F}$ synthases at induced and spontaneous labour onset in the sheep. $J$ Endocrinol. 2004; 180: 469-477.

Parent J, Fortier MA. Expression and contribution of three different isoforms of prostaglandin E synthase in the bovine endometrium. Biol Reprod. 2005; 73: $36-44$.

Parent J, Chapdelaine P, Sirois J, Fortier MA. Expression of microsomal prostaglandin E synthase in bovine endometrium: coexpression with cyclooxygenase type 2 and regulation by interferontau. Endocrinol. 2002; 143: 2936-2943.

Poirier F, Robertson EJ. Normal development of mice carrying a null mutation in the gene encoding the L14 S-type lectin. Dev. 1993; 119: 1229-1236.

Roberts RM, Ealy AD, Alexenko AP, Han CS, Ezashi T. Trophoblast interferons, Placenta. 1999; 20: 259264.

Saugandhika S, Malik HN, Singhal DK, Singhal R, Dubey A, Boateng S, et al. Identification of the relatively predominant buffalo Interferon tau isoform and its expression in Escheria Coli. Reprod Fertil Dev. 2013; 26(1): 174-174.

Sharma D, Niranjana SK, Kumar S, Deb SM, Naskar S, Sharma A, et al. Molecular Characterization of Bubaline Integrin $\beta 2$ (ITGB2) cDNA. J Applied Anim Res. 2010; 37(2): 217-220.

Smalley DM, Ley K. L-selectin: mechanisms and physiological significance of ectodomain cleavage. $J$ Cell Mol Med. 2005; 9: 255-266.

Spencer TE, Johnson GA, Bazer FW, Burghardt RC. Implantation mechanisms: insights from the sheep. Reprod. 2004; 128: 657-668.

Spencer TE, Bazer FW. Ovine interferon tau suppresses transcription of the estrogen receptor and oxytocin receptor genes in the ovine endometrium. Endocrinol. 1996; 137: 1144-1147.

Spencer TE, Ott TL, Bazer FW. Tau-interferon: Pregnancy recognition signal in ruminants. Proc Soc Exp Biol Med. 1996; 213: 215-229.

Tanioka T, Nakatani Y, Semmyo N, Murakami M, Kudo I. Molecular identification of cytosolic prostaglandin E synthase that is functionally coupled with cyclooxygenase-1 in immediate prostaglandin $\mathrm{E}$ biosynthesis. J Biol Chem. 2000; 275: 32775-32782.

Tantia MS, Mishra B, Bharani KST, Mishra BP, Kataria RS, Mukesh M,et al. Characterization of Osteopontin gene of Bubalus bubalis. Anim. 2008; 2(7): 987-990.

Von WM, Wang X, Gabius HJ, Strowitzki T. Galectin fingerprinting in human endometrium and decidua during the menstrual cycle and in early gestation. Mol Hum Reprod. 2005; 11: 189-194. 
Waclawik A, Rivero-Muller A, Blitek A, Kaczmarek MM, Brokken LJS, Watanabe K, et al. Molecular cloning and spatiotemporal expression of prostaglandin $\mathrm{F}$ synthase and microsomal prostaglandin E synthase-1 in porcine endometrium. Endocrinol. 2006; 147: 210-221.

Xiao CW, Murphy BD, Sirois J, Groff AK. Downregulation of oxytocin induced cycloxygenase2 and prostaglandin $\mathrm{F}$ synthase expression by interferon-tau in bovine endometrial cells. Biol Reprod. 1999; 60: 656-663.

Xiao CW, Liu JM, Sirois J, Goff AK. Regulation of cyclooxygenase-2 and prostaglandin $\mathrm{F}$ synthase gene expression by steroid hormone and interferon tau in bovine endometrial cells. Endocrinol. 1998; 139: 2293-2299. 